\title{
Investigation of angiogenetic axis Angiopoietin-1 and -2/Tie-2 in fibrotic lung diseases: A bronchoalveolar lavage study
}

\author{
GIORGOS A. MARGARITOPOULOS ${ }^{1,2}$, KATERINA M. ANTONIOU ${ }^{1,2}$, KOSTAS KARAGIANNIS $^{2}$, \\ EVI VASSALOU ${ }^{2}$, ISMINI LASITHIOTAKI ${ }^{2}$, IRINI LAMBIRI ${ }^{1}$ and NIKOS M. SIAFAKAS ${ }^{1}$ \\ ${ }^{1}$ Interstitial Lung Disease Unit, Department of Thoracic Medicine, University Hospital of Heraklion; ${ }^{2}$ Laboratory of \\ Molecular and Cellular Pulmonary Medicine, Medical School, University of Crete, Heraklion, Crete, Greece
}

Received August 2, 2010; Accepted September 16, 2010

DOI: $10.3892 /$ ijmm_00000543

\begin{abstract}
Increasing evidence implicates angiogenesis in the pathogenesis of fibrotic lung diseases. Distinct angiogenic profiles may, in part, explain differences in immunopathogenesis, clinical course and prognosis. The aim of the study was to seek evidence of involvement of the angiogenic axis Angiopoietin-1 and -2 and their tyrosine kinase receptor, Tie-2 in pathogenesis of idiopathic pulmonary fibrosis (IPF) and interstitial pneumonias associated to collagen tissue disorders (CTD-IPs). We prospectively studied 36 patients with IPF, 23 patients with CTD-IP and 10 healthy subjects. Ang-1, Ang-2 and Tie-2 mRNA expression and protein levels were measured in bronchoalveolar lavage fluid pellets and supernatants, respectively. A statistically significant decrease of Ang-1 protein level has been found in IPF in comparison to controls $(\mathrm{p}=0.02)$. We also detected an increased expression of Ang-2 protein in IPF in comparison to CTD-IPs. A significant co-expression was detected between Ang-2 and Tie-2 in protein level $(\mathrm{p}=0.007)$ in IPF group. In conclusion, a suppression of the angiogenetic factor Ang-1 was observed at the protein level in IPF which may be important in the pathogenesis of this devastating disease. A differential angiogenetic profile regarding Ang-2 was detected between IPF and CTD-IPs.
\end{abstract}

\section{Introduction}

Angiogenesis, the growth of blood vessels from existing ones, is a fundamental biological process that controls embryonic development but is also implicated in numerous life-threatening processes such as pathogenesis of fibroproliferative lung diseases including idiopathic interstitial pneumonias (IIPs) and interstitial pneumonias associated

Correspondence to: Dr Katerina M. Antoniou, Interstitial Lung Disease Unit, Department of Thoracic Medicine, University Hospital, Heraklion 71110, Crete, Greece

E-mail: katerinaantoniou@yahoo.gr

Key words: angiogenesis, angiopoietins, tyrosine kinase receptors with collagen tissue disorders (CTD-IPs) (1-4). It has a significant contribution to the fibroproliferation and extracellular matrix deposition which characterize these diseases $(5,6)$. Angiogenesis is controlled by the interplay of numerous positive and negative factors $(7,8)$. It is still controversial whether angiogenesis has a negative or a positive regulatory role in the pathogenesis of fibrosis.

The concept of vascular remodelling was first raised by Turner-Warwick in IPF (1). Two elegant morphological studies have confirmed the presence of vascular remodelling in IPF by demonstrating that this process is active in the areas immediately adjacent to fibroblastic foci whereas there is a decreased vascular density within the fibroblastic foci $(2,3)$. Moreover, in the study by Renzoni et al this observation was also made in a CTD with pulmonary involvement such as fibrosing alveolitis associated with systemic sclerosis (2). Keane et al demonstrated angiogenic activity in a large number of lung samples with idiopathic pulmonary fibrosis (9), and Ebina et al (10) found both increased capillary density and vascular regression in the same lung at different sites, raising the question of whether angiogenesis is positively or negatively regulated during the process of pulmonary fibrosis.

The biological axis of Angiopoietin-1 and -2 (Ang-1 and -2) and their endothelium-specific receptor tyrosine kinase Tie-2, is implicated in the process of angiogenesis. Ang-1 stabilizes blood vessels by promoting the interaction between endothelial cells and the surrounding extracellular matrix whereas Ang-2 acts as a natural antagonist of Ang-1 by binding to Tie-2 competitively and destabilising blood vessels (11). However, the vessels destabilized by the action of Ang-2 may not regress but undergo angiogenic changes in the presence of angiogenic factors such as vascular endothelial growth factor (VEGF).

The role of this axis has been explored in cancer growth, maintenance and metastasis (11), in the development of chronic hypoxic pulmonary hypertension (12), in chronic obstructive pulmonary disease (13), in asthma (14) and in the pathogenesis of exudative pleural effusions (15).

The purpose of the current study was to investigate the implication of the biological axis Ang-1 and -2/Tie-2 in the pathogenesis of idiopathic and autoimmune lung fibrosis evaluating the mRNA expression and the protein level of its components in the bronchoalveolar lavage fluid (BALF). 


\section{Materials and methods}

Patients. From April 2006 to January 2009, sixty-nine consecutive patients from the Interstitial Lung Disease Unit of the Department of Thoracic Medicine, University Hospital of Heraklion were enrolled in the study: 36 patients with idiopathic pulmonary fibrosis (IPF), 23 patients with interstitial pneumonias related to CTDs (CTD-IPs) and 10 control subjects. The Ethics committee of our hospital approved the protocol and all patients and controls gave their consent.

$I P F$. The diagnosis was based on internationally accepted clinical and imaging criteria (16). In six cases, diagnosis was made by video-assisted thoracoscopic surgery (VATS), where the histologic diagnosis of Usual Interstitial Pneumonia (UIP) was obtained. In the remaining ten cases diagnosis was made on the basis of clinical and high-resolution computed tomography (HRCT) criteria: i) bilateral basal or widespread crackles; ii) restrictive ventilatory defect or isolated reduction of DLCO; iii) computed tomography (CT) findings indicative of IPF i.e., predominantly basal and subpleural microcystic or macrocystic honeycombing, with variably extensive groundglass and reticular abnormalities but no consolidation, nodular abnormalities, or other parenchymal abnormalities (apart from centrilobular emphysema); and iv) no history of environmental exposure to a fibrogenic agent or connective tissue disease (16). According to the afore-mentioned criteria any known cause of pulmonary fibrosis, such as a connective tissue disorder, was excluded by both immunologic screening and rheumatological clinical evaluation.

CTD-IPs. The diagnosis was based on clinical and HRCT criteria in accordance with the international societies guidelines (17-19). In detail, the following patients were studied: a) 10 patients with Rheumatoid Arthritis (RA) and HRCT characteristics of UIP, b) 9 patients with systemic sclerosis (SSc) and HRCT appearance of nonspecific interstitial pneumonia (NSIP), c) 2 patients with systemic lupus erythematous (SLE) one with HRCT features of NSIP and one with HRCT features of UIP, d) one patient with Sjogren syndrome and histologolically proven fibrotic NSIP, and finally e) one patient with dermatomyositis-polymyositis and HRCT features of NSIP.

Pulmonary function tests. All patients were evaluated with complete pulmonary function tests (PFTs) including spirometry, measurement of lung volumes and diffusion capacity. Spirometry, lung volumes using the helium-dilution technique and $\mathrm{T}_{\mathrm{L}, \mathrm{CO}}$ (corrected for haemoglobin) using the single-breath technique were performed using a computerised system (Jaeger 2.12; MasterLab, Würzburg, Germany). Predicted values were obtained from the standardised lung function testing of the European Coal and Steel Community, Luxembourg (1993).

BAL fluid processing. BALF was obtained from all patients and processed as previously described (4).

RNA isolation and reverse transcription-polymerase chain reaction
Table I. Primer sequences used for quantitative real-time RT-PCR.

\begin{tabular}{llc}
\hline Gene & \multicolumn{1}{c}{ Primer pair sequence (5'-3') } & $\begin{array}{c}\text { Annealing } \\
\text { temperature }\end{array}$ \\
\hline Ang-1 & $\begin{array}{l}\text { F: TTAATGGACTGGGAAGGGAACC } \\
\text { R: AGGGGCCACAAGCATCAAA }\end{array}$ & $55^{\circ} \mathrm{C}$ \\
Ang-2 & $\begin{array}{l}\text { F: AGCCGGCAAAATAAGCAGCATC } \\
\text { R: GGTTGTGGCCTTGAGCGAATAGC }\end{array}$ & $59^{\circ} \mathrm{C}$ \\
Tie2A & $\begin{array}{l}\text { F: GGGCATCCTGGACCTGTGAGAC } \\
\text { R: CCCCTGGGCCTTGGTGTTGACT }\end{array}$ & $64^{\circ} \mathrm{C}$ \\
Tie2B & $\begin{array}{l}\text { F: AATGAGACAATGCTGGCGGGAGAA } \\
\text { R: ATGCCAGTGAAAGGGAAACAGAGG }\end{array}$ & $64^{\circ} \mathrm{C}$ \\
GAPDH & F: GGAAGGTGAAGGTCGGAGTCA & $60^{\circ} \mathrm{C}$ \\
& R: GTCATTGATGGCAACAATATCCACT & \\
\hline
\end{tabular}

RNA extraction and reverse transcription. Total RNA was extracted from each specimen using a power homogenizer and the TRIzol ${ }^{\circledR}$ reagent (Invitrogen, Carlsband, CA) according to the manufacturer's instructions. cDNA was synthesized using the Strascript reverse transcriptase kit (Stratagene, La Jolla, CA) as previously described (4).

Real-time RT-PCR. Ang-1, Ang-2 and Tie-2 mRNA expression was measured using a real-time RT-PCR assay with SYBR-Green I. Primers were designed to span introns. Glyceraldehyde-3-phosphate dehydrogenase (GAPDH) was used as the internal control, in order to normalize Ang-1, Ang-2, Tie-2. Specifically, $1 \mu \mathrm{l}$ cDNA from all patient and control samples was amplified in a PCR reaction containing 2X Brilliant SYBR-Green I QPCR Master mix, $300 \mathrm{nM}$ of each primer and $30 \mu \mathrm{M}$ ROX passive reference dye, in a final volume of $20 \mu 1$. After an initial denaturation at $95^{\circ} \mathrm{C}$ for $10 \mathrm{~min}$, the samples were subjected to 40 cycles of amplification, comprised of denaturation at $95^{\circ} \mathrm{C}$ for $30 \mathrm{sec}$, annealing at appropriate temperature for each primer pair for $30 \mathrm{sec}$ and elongation at $72^{\circ} \mathrm{C}$ for $30 \mathrm{sec}$, followed by a melt curve analysis, in which the temperature was increased from $55^{\circ} \mathrm{C}$ to $95^{\circ} \mathrm{C}$ at a linear rate of $0.2^{\circ} \mathrm{C} / \mathrm{sec}$.

Data collection was performed both during annealing and extension, with two measurements at each step, and at all times during melt curve analysis. In each PCR reaction two non-template controls were included. All PCR experiments were conducted on the Mx3000P real-time PCR thermal cycler using the software version 2.00 (Stratagene). To verify the results of the melt curve analysis, PCR products were analyzed by electrophoresis in $2 \%$ agarose gels, stained with ethidium bromide and photographed on a UV light transilluminator.

Primer sequences, annealing temperatures and PCR product length for all the genes analyzed, as well as for GAPDH, are shown in Table I. All reactions were run in triplicates, and peptide transcript levels were calculated and normalized to each specimen's housekeeping gene mRNA (GAPDH) as well as the appropriate calibrators, using the $\Delta \Delta \mathrm{Ct}$ method for relative quantification. Specifically, after 
Table II. Demographic and lung function characteristics of patients with IPF and CTD-IP and control subjects.

\begin{tabular}{|c|c|c|c|c|c|c|}
\hline Characteristics & IPF & CTD-IP & Control & $\mathrm{p}^{\mathrm{d}}$ & $\mathrm{p}^{\mathrm{e}}$ & $\mathrm{p}^{\mathrm{f}}$ \\
\hline Number & 36 & 23 & 10 & & & \\
\hline $\mathrm{Age}^{\mathrm{b}}$ & $70 \pm 1.43$ & $61.13 \pm 3.66$ & $59.22 \pm 3$ & 0.009 & NS & 0.036 \\
\hline Gender (male/female) ${ }^{c}$ & $29 / 7$ & $4 / 18$ & $7 / 3$ & NS & 0.001 & $<10^{-4}$ \\
\hline Smokers $^{c}$ & 10 & 4 & 7 & 0.014 & 0.003 & NS \\
\hline Ex-smokers ${ }^{\mathrm{c}}$ & 13 & 1 & 1 & NS & NS & 0.005 \\
\hline Non-smokers ${ }^{\mathrm{c}}$ & 13 & 18 & 2 & NS & 0.001 & 0.001 \\
\hline $\mathrm{FEV}^{\mathrm{b}}$ & $80.44 \pm 2.98$ & $80.24 \pm 5.4$ & $86.4 \pm 7.17$ & NS & NS & NS \\
\hline $\mathrm{FVC}^{\mathrm{b}}$ & $76.97 \pm 2.68$ & $77.29 \pm 4.31$ & $92.6 \pm 6.75$ & 0.05 & NS & NS \\
\hline FEV1/FVC & $82.19 \pm 1.94$ & $81.29 \pm 2.9$ & $75 \pm 4$ & NS & NS & NS \\
\hline $\mathrm{TLC}^{\mathrm{b}}$ & $74.12 \pm 2.83$ & $82.65 \pm 4.32$ & $108.4 \pm 2.86$ & $<10^{-4}$ & $<10^{-4}$ & NS \\
\hline $\mathrm{DLCO}^{\mathrm{b}}$ & $52.72 \pm 3.92$ & $55.2 \pm 4.8$ & $77.2 \pm 6.98$ & 0.008 & 0.018 & NS \\
\hline
\end{tabular}

${ }^{\mathrm{a}}$ Values are expressed as mean \pm SEM (standard error of the mean). ${ }^{\mathrm{b}} \mathrm{T}$-test; ${ }^{\mathrm{c}} \chi^{2}$-test, $\mathrm{p}<0.05$, statistically significant (in bold); NS, not significant. $\mathrm{p}^{\mathrm{d}}$, p-value between IPF and controls; $\mathrm{p}^{\mathrm{e}}$, $\mathrm{p}$-value between CTD-IP and controls; $\mathrm{p}^{\mathrm{f}}$, $\mathrm{p}$-value between CTD-IP and IPF. FEV1, forced expiratory volume in one second; FVC, forced vital capacity; TLC, total lung capacity; $\mathrm{DL}_{\mathrm{CO}}$, diffusing capacity for carbon monoxide.

Table III. Expression profile of mRNA and protein levels of the genes. ${ }^{\mathrm{a}}$

\begin{tabular}{lccccccc}
\hline & \multicolumn{3}{c}{ Expression (\%) } & & & \\
\cline { 2 - 4 } Gene & IPF & CTD-IP & Control & & $\mathrm{p}^{\mathrm{b}}$ & $\mathrm{p}^{\mathrm{c}}$ & $\mathrm{p}^{\mathrm{d}}$ \\
\hline Ang-1 mRNA & $0 / 28$ & $0 / 21$ & $0 / 10$ & NS & NS & NS \\
Ang-1 protein & $8 / 27$ & $6 / 15$ & $6 / 10$ & NS & NS & NS \\
Ang-2 mRNA & $3 / 28$ & $1 / 21$ & $0 / 10$ & NS & NS & NS \\
Ang-2 protein & $\mathbf{2 7 / 2 7}$ & $\mathbf{1 3 / 1 5}$ & $10 / 10$ & NS & NS & $\mathbf{0 . 0 5}$ \\
Tie-2 mRNA & $0 / 28$ & $0 / 21$ & $0 / 10$ & NS & NS & NS \\
Tie-2 protein & $17 / 27$ & $9 / 15$ & $8 / 10$ & NS & NS & NS \\
\hline
\end{tabular}

${ }^{\mathrm{a}} \chi^{2}$-test, $\mathrm{p}<0.05$, statistically significant (in bold); NS, not significant. ${ }^{b} \mathrm{p}$, p-value between IPF and controls; ${ }^{c} \mathrm{p}$, p-value between CTD-IP and controls; ${ }^{\mathrm{d}} \mathrm{p}, \mathrm{p}$-value between CTD-IPs and IPF.

amplification, standard curves were constructed from samples used in a series of consecutive dilutions, for both the gene of interest and the internal control (GAPDH). Ang-1, Ang-2, Tie-2 and GAPDH amplification efficiencies were the same, reaching $100 \%$. IPF and control data were first normalized against variation in sample quality and quantity. Normalized values to GAPDH, $\Delta \mathrm{Cts}$, were initially calculated using the following equation: $\Delta \mathrm{Ct}_{\text {sample }}=\mathrm{Ct}_{\text {gene }}-\mathrm{Ct}_{\mathrm{GAPDH}}$.

Assay of angiogenic parameter protein levels using specific enzyme-linked immunosorbent assay. Human BALF protein levels of Ang-1, Ang-2 and Tie-2 were quantitated according to the manufacturer's protocol using ELISA kits (R\&D Systems) and measurements were performed in the BALF supernatant. Human Ang-1, Ang-2 and Tie-2 had the lowest detectable limit of 5 and $10 \mathrm{pg} \cdot \mathrm{ml}^{-1}$, respectively.
Statistical analysis. Angiogenetic parameters and demographic characteristics were first evaluated by the one-sample Kolmogorov-Smirnov goodness of fit test, in order to determine whether they followed a normal distribution pattern. Depending on the results, Mann-Whitney test or T-test were used to examine their expression status between the groups. The non-parametric Spearman rank correlation was used to examine their relation pair-wise. Finally, the Chi-square $\left(\chi^{2}\right)$ test was applied to evaluate the significant statistical differences in Ang-1, Ang-2, Tie-2 mRNA and protein expression status as well as gender (male/female) and smoking status (smokers, non-smokers, ex-smokers). $\mathrm{p}<0.05$ were considered statistically significant. All statistical analyses were performed with SPSS 11.5 (SPSS, Chicago, IL, USA).

\section{Results}

The demographic and spirometric data of healthy controls, IPF and CTD-IP patients are shown in Table II. IPF patients were older than CTD-IPs and healthy subjects with the majority of them being males. There were more IPF patients who were current smokers as well as ex-smokers whereas most of the CTD-IPs patients have never smoked. Both patient groups had a significant decrease in the cardinal parameters of restrictive defect (TLC and DLco).

Expression of Ang-1 and-2/Tie-2 in patients groups and controls. Ang-1 mRNA is not expressed in any of our study groups whereas Ang-1 protein is expressed in 8/27 (29.5\%) in IPF group, in 6/15 (40\%) in CTD-IP group and in 6/10 (60\%) in control subjects. Ang-2 mRNA is expressed in 3/28 (10.7\%) of patients with IPF, in $1 / 21(4.7 \%)$ in the CTD-IP group, whereas it is not expressed in control subjects. Ang-2 protein expression was detectable in all patients with IPF [27/27 $(100 \%)$ ] and in $13 / 15(86.6 \%)$ in CTD-IP group ( $\mathrm{p}=0.05)$, as well as in all control subjects [10/10 (100\%)]. Tie-2 mRNA 
Table IV. mRNA expression and protein level of angiogenetic parameters in IPF, CTD-IP and control subjects. ${ }^{\mathrm{a}}$

\begin{tabular}{|c|c|c|c|c|}
\hline Angiogenetic parameters & IPF & CTD-IP & Control & $\mathrm{p}^{\mathrm{d}}$ \\
\hline Ang-1 mRNA ${ }^{b}$ & 0.00 & 0.00 & 0.00 & NS \\
\hline Ang-1 protein level ${ }^{b}$ & $0.24 \pm 0.14$ & $1.26 \pm 1.06$ & $0.79 \pm 0.25$ & 0.021 \\
\hline Ang-2 mRNA ${ }^{b}$ & $292.36 \pm 283.22$ & $0.025 \pm 0.0248$ & 0.00 & NS \\
\hline Ang-2 protein levelc & $130.8 \pm 25.01$ & $100.11 \pm 19.57$ & $113.33 \pm 25.75$ & NS \\
\hline Tie-2 mRNA & 0.00 & 0.00 & 0.00 & NS \\
\hline Tie-2 protein level ${ }^{\mathrm{c}}$ & $0.158 \pm 0.029$ & $0.163 \pm 0.054$ & $0.108 \pm 0.026$ & NS \\
\hline
\end{tabular}

${ }^{a}$ Values are expressed as the mean \pm SEM (standard error of the mean). ${ }^{b}$ Mann-Whitney test; ${ }^{\mathrm{c}} \mathrm{T}$-test. $\mathrm{p}<0.05$, statistically significant (in bold); NS, not significant. $\mathrm{p}^{\mathrm{d}}$, p-value between IPF and control.
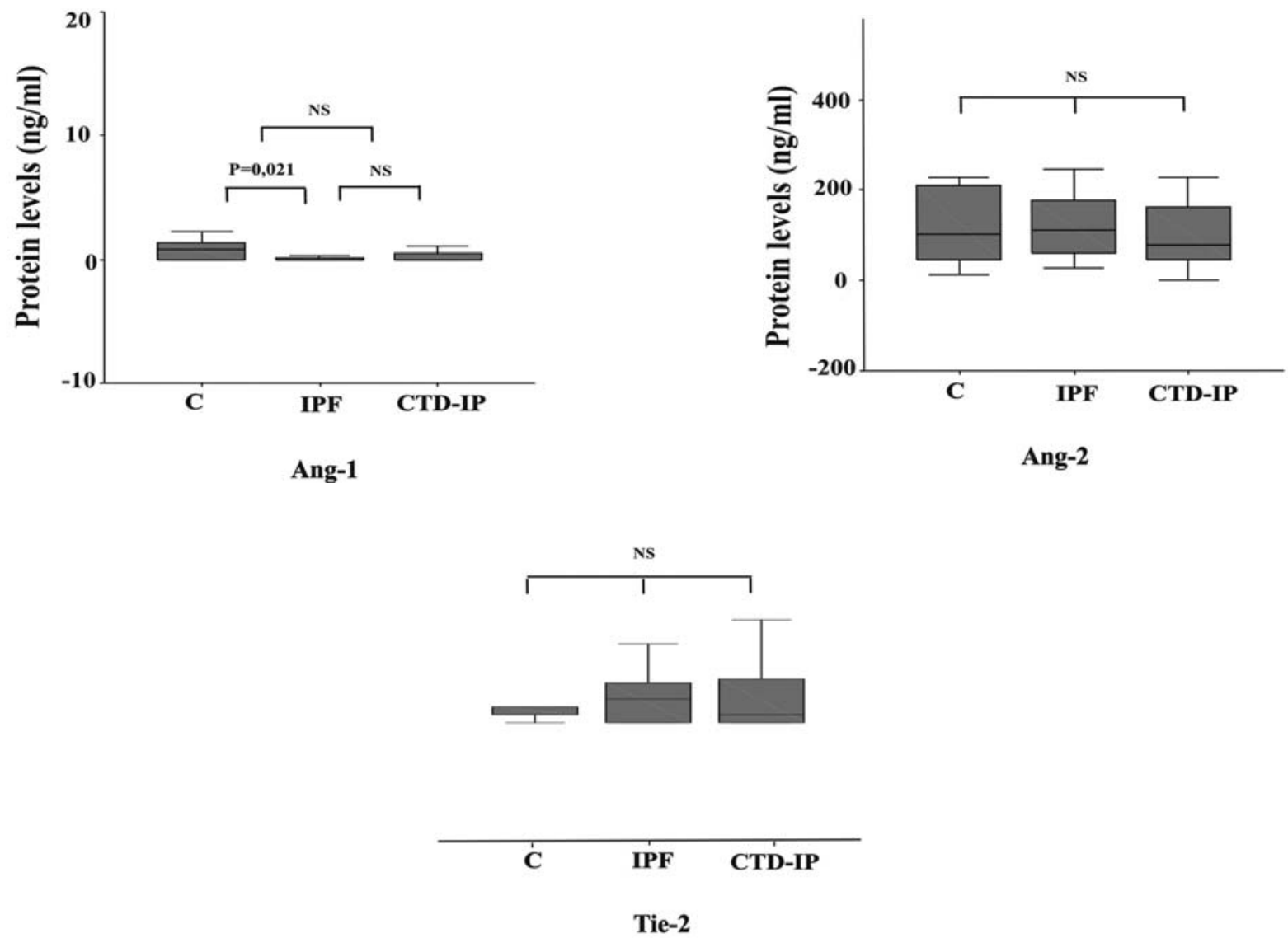

Figure 1. Protein levels of Ang-1, Ang-2 and Tie-2 in patient groups and controls.

was not expressed in our study groups. Tie-2 protein expression was detectable in 17/27 (62.4\%), 9/15 (60\%), and 8/10 (80\%) in IPF, CTD-IPs and control subjects, respectively (Table III).

mRNA expression of Ang-1 and -2/Tie-2 in patient groups and controls. We found no significant difference in mRNA expression of Ang-2 in our study groups (Table IV).

Protein expression of Ang-1 and -2/Tie-2 in patient groups and controls. We found a statistically significant decrease of Ang-1 protein level in IPF in comparison to control subjects (mean $\pm \mathrm{SD}, 0.24 \pm 0.14$ versus $0.79 \pm 0.25, \mathrm{p}=0.021$ ). The increase of Ang-1 protein level in CTD-IP in comparison to
IPF and control did not reach statistical significance. We detected no significant difference in Ang-2 and Tie-2 protein level in our study groups (Table IV and Fig. 1).

Correlations between angiogenic parameters. A significant pair-wise correlations between Ang-2 and Tie-2 in protein level was observed in IPF group $(\mathrm{p}=0.007$ Spearman correlation).

\section{Discussion}

To the best of our knowledge this is the first study that investigated the role of Ang-1, Ang-2 and their receptor Tie-2 
in the pathogenesis of IPF and CTD-IPs. We used the BAL fluid, a minimally invasive tool, in order to evaluate the mRNA and protein expression of these angiogenic parameters.

We observed a decrease of Ang-1 at the protein level in IPF patients compared to controls, suggesting a downregulation of angiogenesis. Additionally, a significant co-expression between Ang-2 and Tie-2 in protein level was found in the IPF group suggesting a possible increase of angiostatic activity in IPF. This could be a novel pathway involved in the pathogenetic process of IPF.

We also observed that Ang-2 protein was significantly expressed in more patients with IPF in comparison to CTD-IP and that Ang-2 protein levels were increased, although not significantly in IPF compared to CTD-IPs. This finding might be evidence of distinct angiogenic profile between IPF and CTD-IPs, which explains the well known difference in terms of prognosis and response to therapy between these two diseases (20). Recently, our study group demonstrated that angiogenesis could differ between CTD-IPs and IPF showing a significantly higher level in both mRNA and protein expression of stromal cell derived factor- $1 \alpha$ transcript 1 (SDF-1 $\alpha$-TR1), a potent angiogenic factor, in BAL fluid of patients with CTD-IPs in comparison to IPF patients (21). In addition, we found a post-transcriptional overexpression of VEGF, a major angiogenic factor, in CTD-IPs when compared to patients with NSIP (21). Moreover, we suggested that distinct angiogenic profiles could also explain differences in the pathogenesis and prognosis between fibrotic and granulomatous disorders $(4,22)$.

It should be stressed that our study has some limitations that need consideration. It is not a morphological study since we have used BAL fluid and not lung tissue. This is due to the fact that surgical lung biopsy is often not warranted for the diagnosis of IPF (16). On the other hand, surgical biopsy does not add more information on the diagnosis and prognosis of CTD-IP, except in cases with unusual high resolution computerised tomography scan appearances (20). Moreover, CTD-IPs have better prognosis than IPF even when they present with a UIP pattern in lung biopsy (17). Another limitation is the small number of CTD-IPs patients for whom it was not possible to analyze data separately for individual CTDs and for individual histologic pattern.

In conclusion, the current study is the first to investigate the angiogenetic axis of Angiopoietins-1 and -2 and their specific receptor Tie-2 in pulmonary fibrosis, both idiopathic and autoimmune. Our findings add to the understanding of the role of angiogenesis in the pathogenesis of lung fibrosis. However, further studies are needed to confirm these findings.

\section{Acknowledgements}

The authors would like to thank Dr Giannoula Soufla and Mrs. Rena Lymbouridou for performing the primers design and the statistical analysis.

\section{References}

1. Turner-Warwick M: Precappilary systemic-pulmonary anastomoses. Thorax 18: 225-237, 1963.
2. Renzoni EA, Walsh DA, Salmon M, et al: Interstitial vascularity in fibrosing alveolitis. Am J Respir Crit Care Med 167: 438-443, 2003.

3. Cosgrove GP, Brown KK, Schiemann WP, et al: Pigment epithelium-derived factor in idiopathic pulmonary fibrosis: a role in aberrant angiogenesis. Am J Respir Crit Care Med 170: 242-251, 2004.

4. Antoniou KM, Tzouvelekis A, Alexandrakis MG, et al: Different angiogenic activity in pulmonary sarcoidosis and idiopathic pulmonary fibrosis. Chest 130: 982-988, 2006.

5. Noble PW: Idiopathic pulmonary fibrosis. New insights into classification and pathogenesis usher in a new era therapeutic approaches. Am J Respir Cell Mol Biol 29: S27-S31, 2003.

6. Antoniou KM, Pataka A, Bouros D and Siafakas NM: Pathogenetic pathways and novel pharmacotherapeutic targets in idiopathic pulmonary fibrosis. Pulm Pharmacol Ther 20: 453-461, 2007.

7. Strieter RM, Burdick MD, Gomperts BN, Belperio JA and Keane MP: CXC chemokines in angiogenesis. Cytokine Growth Factor Rev 16: 593-609, 2005.

8. Strieter RM, Belperio JA and Keane MP: CXC chemokines in angiogenesis related to pulmonary fibrosis. Chest 122: S298-S301, 2002.

9. Keane MP, Belperio JA, Burdick MD, Lynch JP, Fishbein MC and Strieter RM: ENA-78 is an important angiogenic factor in idiopathic pulmonary fibrosis. Am J Respir Crit Care Med 164: 2239-2242, 2001

10. Ebina M, Shimizukawa M, Shibata N, et al: Heterogeneous increase in CD34-positive alveolar capillaries in idiopathic pulmonary fibrosis. Am J Respir Crit Care Med 169: 1203-1208, 2004.

11. Economidou F, Margaritopoulos G, Antoniou KM and Siafakas NM: The angiogenetic pathway in malignant pleural effusions: Pathogenetic and therapeutic implications. Exp Therap Med 1: 3-7, 2010.

12. Folkman J, Watson K, Ingber D and Hanahan D: Induction of angiogenesis during the transition from hyperplasia to neoplasia. Nature 339: 58-61, 1989.

13. Yancopoulos GD, Davis S, Gale NW, Rudge JS, Wiegand SJ and Holash J: Vascular-specific growth factors and blood vessel formation. Nature 407: 242-248, 2000.

14. Toi M, Taniguchi T, Yamamoto Y, Kurisaki T, Suzuki H and Tominaga T: Clinical significance of the determination of angiogenic factors. Eur J Cancer 32A: 2513-2519, 1996.

15. Economidou F, Antoniou KM, Tzanakis N, Sfiridaki K, Siafakas NM and Schiza SE: Angiogenic molecule Tie-2 and VEGF in the pathogenesis of pleural effusions. Respir Med 102: 774-779, 2008.

16. American Thoracic Society/European Respiratory Society: International Multidisciplinary Consensus Classification of the Idiopathic Interstitial Pneumonias. Am J Respir Crit Care Med 165: 277-304, 2002.

17. Park JH, Kim DS, Park IN, Jang SJ, Kitaichi M, Nicholson AG and Colby TV: Prognosis of fibrotic interstitial pneumonia: idiopathic versus collagen vascular disease-related subtypes. Am J Respir Crit Care Med 175: 705-711, 2007.

18. American Rheumatism Association Diagnostic and Therapeutic Criteria Subcommittee for Scleroderma: Preliminary criteria for the classification of systemic sclerosis (scleroderma). Subcommittee for scleroderma criteria of the American Rheumatism Association Diagnostic and Therapeutic Criteria Committee. Arthritis Rheum 23: 581-590, 1988

19. Arnett FC, Edworthy SM, Bloch DA, et al: The American Rheumatism Association 1987 revised criteria for the classification of rheumatoid arthritis. Arthritis Rheum 31: 315-324, 1988.

20. Antoniou KM, Margaritopoulos G, Economidou F and Siafakas NM: Pivotal clinical dilemmas in collagen vascular diseases associated with interstitial lung involvement. Eur Respir J 33: 882-896, 2009.

21. Margaritopoulos GA, Antoniou KM, Soufla G, et al: Upregulation of stromal cell derived factor-1alpha in collagen vascular diseases-associated interstitial pneumonias (CVDs-IPs). Pulm Pharmacol Ther 23: 115-120, 2010.

22. Antoniou KM, Soufla G, Proklou A, et al: Different activity of the biological axis VEGF - Flt-1 (fms-like tyrosine kinase 1) and CXC chemokines between granulomatous and fibrotic disorders: a bronchoalveolar lavage study. Clin Dev Immunol 2009: 537929, 2009. 